Check for updates

Cite this: J. Anal. At. Spectrom., 2019, 34,2147

DOI: 10.1039/c9ja90051a

www.rsc.org/jaas

\section{Correction: Rapid, versatile and sensitive method for the quantification of radium in environmental samples through cationic extraction and inductively coupled plasma mass spectrometry}

\author{
Claire Dalencourt, Annie Michaud, Azza Habibi, Alexa Leblanc and Dominic Larivière*
}

Correction for 'Rapid, versatile and sensitive method for the quantification of radium in environmental samples through cationic extraction and inductively coupled plasma mass spectrometry' by Claire Dalencourt et al., J. Anal. At. Spectrom., 2018, 33, 1031-1040.

The authors regret that Fig. 1 and 4 of the original article contained errors in the units of the ${ }^{226}$ Ra concentration. Due to an error during conversion from activities to mass (Bq to g), the concentrations of ${ }^{226} \mathrm{Ra}$ in Fig. 1 and 4 should be expressed in pg L $\mathrm{L}^{-1}$ instead of fg $\mathrm{L}^{-1}$. The correct versions of Fig. 1 and 4 are displayed below. In addition, a correction to the units in the text should be made on page 1033, fifth paragraph at the right. The correct paragraph should read as follows:

The influence of the sample loading flow rate and the loaded volume on the retention of radium was investigated using a solution containing ${ }^{226} \mathrm{Ra}$ to obtain a final concentration of ${ }^{226} \mathrm{Ra}$ in the elution fraction of $273 \mathrm{pg} \mathrm{L}^{-1}\left(10 \mathrm{~Bq} \mathrm{~L}^{-1}\right)$.

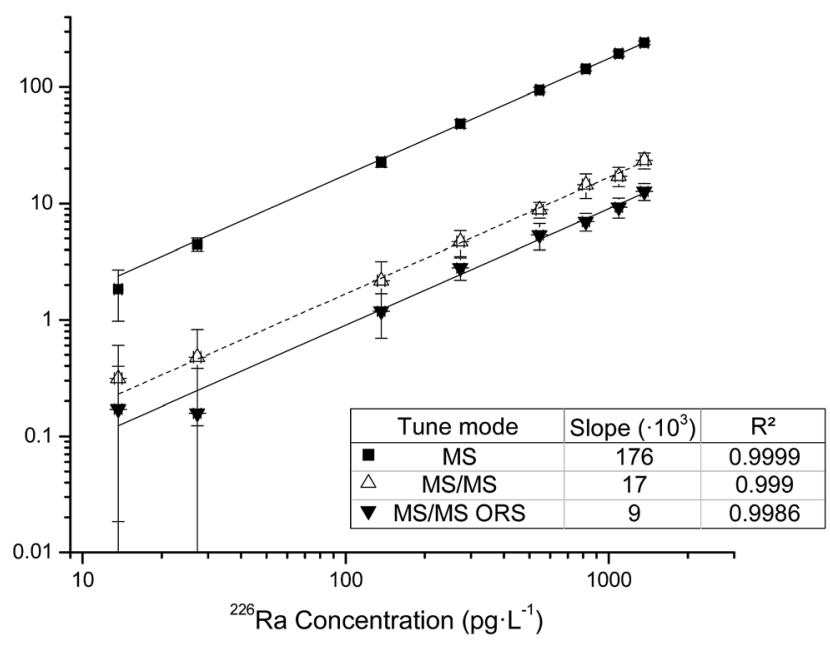

Fig. $1{ }^{226}$ Ra calibration curves in various ICP-MS configuration. 


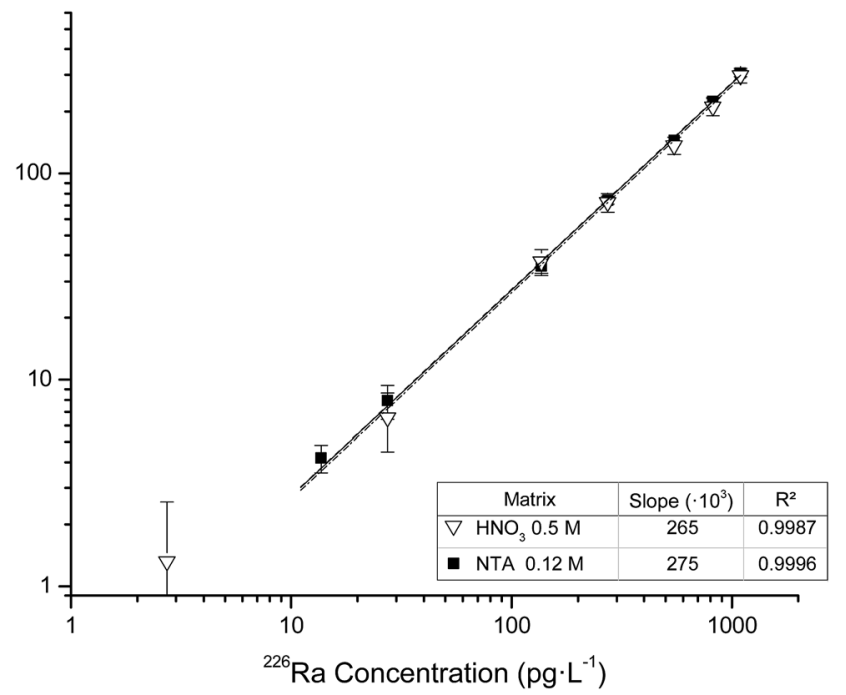

Fig. $4{ }^{226}$ Ra calibration curves in various instrumental configurations.

The Royal Society of Chemistry apologises for these errors and any consequent inconvenience to authors and readers. 